\title{
Thermochemical structure and evolution of cratonic lithosphere in central and southern Africa
}

\author{
Juan C. Afonso ${ }^{1, *}$, Walid Ben-Mansour ${ }^{1,2}$, Suzanne Y. O'Reilly ${ }^{1}$, William L. Griffin ${ }^{1}$, \\ Farshad Salajeghegh ${ }^{1}$, Stephen Foley ${ }^{1}$, Graham Begg ${ }^{1}$, Kate Selway ${ }^{3}$, Andrew \\ Macdonald $^{4}$, Nicole Januszczak ${ }^{5}$, llya Fomin ${ }^{1}$, Andrew A. Nyblade ${ }^{6}$, Yingjie Yang ${ }^{1}$ \\ ${ }^{1}$ ARC Centre of Excellence for Core to Crust Fluid Systems (CCFS), Department of Earth and \\ Environmental Sciences, Macquarie University, North Ryde, Australia. \\ 2 Department of Earth and Planetary Sciences, Washington University, St Louis, USA. \\ ${ }^{3}$ Future Industries, University of South Australia \\ ${ }^{4}$ De Beers Group Services, Johannesburg, South Africa. \\ ${ }^{5}$ BHP Technical Centre of Excellence, Perth, Australia. \\ ${ }^{6}$ Department of Geosciences, Pennsylvania State University, USA.
}

Corresponding author: juan.afonso@mq.edu.au

This manuscript is a precopyedited, author produced EarthArXiv PrePrint that has been submitted for publication in Nature Geoscience with minor revisions. Subsequent versions of this manuscript may have different content. The final version of this manuscript will be available via the publication link on the right-hand side of this website link. 


\section{Thermochemical structure and evolution of cratonic litho- sphere in central and southern Africa}

Juan C. Afonso ${ }^{1, *}$, Walid Ben-Mansour ${ }^{1,2}$, Suzanne Y. O’Reilly ${ }^{1}$, William L. Griffin ${ }^{1}$, Farshad Salajeghegh ${ }^{1}$, Stephen Foley ${ }^{1}$, Graham Begg $^{1}$, Kate Selway $^{3}$, Andrew Macdonald $^{4}$, Nicole Januszczak $^{5}$, Ilya Fomin ${ }^{1}$, Andrew A. Nyblade ${ }^{6}$, Yingjie Yang ${ }^{1}$

${ }^{1}$ ARC Centre of Excellence for Core to Crust Fluid Systems (CCFS), Department of Earth and Environmental Sciences, Macquarie University, North Ryde, Australia.

${ }^{2}$ Department of Earth and Planetary Sciences, Washington University, St Louis, USA.

${ }^{3}$ Future Industries Institute, University of South Australia.

${ }^{4}$ De Beers Group Services, Johannesburg, South Africa.

${ }^{5}$ BHP Technical Centre of Excellence, Perth, Australia.

${ }^{6}$ Department of Geosciences, Pennsylvania State University, USA.

7*juan.afonso@mq.edu.au

The thermochemical structure of the subcontinental mantle holds crucial information on its origin and evolution that can inform energy and mineral exploration strategies, natural hazard mitigation and evolutionary models of the Earth ${ }^{1-4}$. However, imaging the fine-scale thermochemical structure of continental lithosphere remains a major challenge. Here we combine multiple land and satellite datasets via thermodynamically-constrained inversions to obtain a high-resolution thermochemical model of central and southern Africa. Results reveal diverse structures and compositions for cratons, indicating distinct evolutions and re- 
sponses to geodynamic processes. While much of the Kaapvaal lithosphere retained its cratonic features, the western Angolan-Kasai shield and the Rehoboth block have lost their cratonic keels. The lithosphere of the Congo Craton has been affected by metasomatism, increasing its density and inducing its conspicuous low-topography, geoid and magnetic anomalies. Our results reconcile mantle structure with the causes and location of volcanism within and around the Tanzanian Craton, whereas the absence of volcanism towards the north is the result of local asthenospheric downwellings, not to a previously-proposed lithospheric root connecting with the Congo Craton. Our study offers greatly improved integration of mantle structure, magmatism and the evolution and destruction of cratonic lithosphere and lays the groundwork for new evolutionary models and exploration frameworks for the Earth and other terrestrial planets.

Main

The thermochemical structure of the lithosphere exerts important controls on the localization of seismic activity, magmatism and giant ore deposits ${ }^{1-3}$. Information on lithosphere-scale structure is rapidly becoming an important component of modern exploration and hazard-mitigation frameworks ${ }^{1,4-7}$. It is also essential to understanding the origin, evolution and destruction of cratons and the physico-chemical interactions between the lithosphere and the sublithospheric mantle.

Despite its fundamental importance, imaging the fine-scale thermochemical structure of the lithosphere from geophysical data has proven difficult. While temperatures obtained from different methods broadly agree, the simultaneous characterization of the mineralogical and major- 
element chemical structure (essential for resource exploration) from geophysical data is significantly more complex and enigmatic ${ }^{8-13}$. Consequently, the analysis of mantle samples (i.e., xenoliths, xenocrysts) brought to the surface by volcanoes is still considered the only reliable approach. Such samples, however, are scattered in space and time, and the interpolations needed for regionalscale predictive models involve large and unquantifiable uncertainties.

Here we show that the formal integration of high-resolution, land and satellite geophysical datasets offers a salient and viable alternative to the study of mantle samples. This is due to the better spatial coverage and improved sensitivity to the thermochemical structure of the lithosphere that results from exploiting the complementary nature of these datasets ${ }^{11-13}$. We demonstrate the value of this approach using a probabilistic joint inversion method that fuses multiple geophysical datasets with the sensitivities required to image the thermal and compositional structures of the lithosphere and sublithospheric upper mantle (Methods). We focus on central and southern Africa, a region that encapsulates 3.5 billion years of evolution and hosts the Kalahari, Tanzanian and Congo cratons, and a number of microcontinental cratonic blocks (e.g. Kaapvaal, Zimbabwe, Angola and Bangweulu). This region is an excellent natural laboratory to probe fundamental questions about craton evolution, not only due to the large extent of cratonic lithosphere, but also because some domains have been affected by convergent margin and/or mantle plume activity with different impacts on thermochemical structure ${ }^{14}$, while others have not. It also supplied abundant xenolith-derived datasets that provide groundtruthing for the joint inversion approach used here.

We combined broadband seismic data from 870 stations in the study region with global and 
regional surface-wave data to obtain a high-resolution, consistent dataset of Rayleigh-wave dispersion curves (Methods). Geoid and gravity anomalies, elevation, surface heat flow, and gravity gradients were also used in our inversion. The spatial resolution and complementary sensitivities of these datasets to bulk density and shear-wave velocity allow us to image the thermochemical structure of the central-south African lithosphere with unprecedented resolution and confidence.

\section{Lithospheric thermochemical structure}

Tomographic studies have highlighted a significant correlation between the extents of cratonic domains inferred by crustal elements and high mantle wavespeeds ${ }^{15-17}$, suggesting that cratonic crust and the underlying lithospheric mantle root remain coupled through time. Our results indicate that this is not always the case (Fig. 1). The extent of anomalously thick lithosphere in central and southern Africa is significantly smaller than that inferred from surface geology, requiring mechanisms that can erode/destroy the lithospheric mantle without significantly affecting the crust, as suggested by recent high-resolution tomography ${ }^{18}$.

Our derived lithospheric structure exhibits a clear correlation with well-known mid- and large-scale surface structures. This is particularly evident in the East African Rift, the Central Africa Shear Zone (CASZ), the Okahandja Lineament/Mwembeshi Shear zone and the boundaries of the Lufulian Arc (Suppl. Fig. 13). The CASZ is one of the largest shear zones in the continent; according to our results it marks one of the largest steps in the LAB globally: a $\sim 200 \mathrm{~km}$ change in lithospheric thickness over a distance of $\sim 600 \mathrm{~km}$. Notably, one of the world's largest magnetic 
anomalies, the enigmatic Bangui anomaly, is located in this region and is aligned with the imaged thermochemical structure (Suppl. Fig. 15).

On the Atlantic margin, marked lithospheric thinning occurs along the Damaran Belt in Namibia and in the "cratonic" interior of Angola. In both cases, crustal thinning is also apparent (Fig. 3), suggesting that a common tectonic process affected both the crust and the lithospheric mantle. This is consistent with major extensional/transtensional structures that developed in these two regions during the initial opening of the Atlantic Ocean ${ }^{19}$. Our predicted LAB depth beneath Namibia coincides well with a strong and widespread negative conversion at $\sim 80 \mathrm{~km}^{20}$, originally interpreted as a mid-lithosphere discontinuity within a $200-\mathrm{km}$-thick lithosphere ${ }^{20}$. Our results indicate that this conversion instead represents the LAB.

In western Angola, a comparison between thermobarometry-based geotherms and our model reveals $>80 \mathrm{~km}$ thinning of the lithosphere (Suppl. Fig. 16) since kimberlite emplacement (216$\left.252 \mathrm{Ma}^{21}\right)$. Eruption ages and those of major crustal structures are consistent with whole-oflithosphere thinning during the opening of the Atlantic Ocean, with the Tristan Plume (Fig. 3) likely contributing to the weakening and thinning of the lithospheric mantle. Carbonate-rich ultramafic lavas $<1$ Ma old in Angola's Catanda volcanic complex ${ }^{22}$ have been interpreted to originate from local mantle upwelling beneath thinned lithosphere ${ }^{22}$, but the nature and size of the upwelling and the LAB depth were poorly constrained. Our results confirm significant thinning of the lithosphere beneath this region (Fig. 1), but also reveal a hot anomaly in the shallow sublithospheric upper mantle (Fig. 2a), which may explain the carbonatitic and alkaline magmatism in Angola 
and the recent uplift of the Bie Dome. Another clear correlation between thin lithosphere and thin crust is observed along the Western and Eastern branches of the East Africa Rift (Figs. 1 and 3), again suggesting whole-of-lithosphere thinning. Although localized lithospheric thinning beneath the Malawi rift is not discernible in previous large-scale LAB models (Suppl. Fig. 13), it has been imaged in high-resolution studies ${ }^{23}$.

A key feature of our model is a thermochemical anomaly coincident with the Lufilian Arc and its extension into the eastern branch of the Damara Belt (Fig. 1). These two large-scale structures were created during collision of the Kalahari and Congo cratons in the early Paleozoic. Before the collision, both regions experienced widespread extension, producing a failed intracontinental rift in the Lufilian Arc and a marginal oceanic basin in the Damara Belt. Our results show a domain of relatively fertile mantle along the Damara-Katanga belts (Fig. 1), consistent with both belts experiencing multiple periods of collisional orogenesis, rifting and mafic-ultramafic magmatism in the Proterozoic. The net result is that the lithospheric mantle of both zones is thinned and likely to be strongly refertilised. While a coherent mantle compositional anomaly is observed along the Damara and Lufilian domains, the LAB is conspicuously shallow beneath the Lufilian Arc. Its northern boundary is particularly well defined, separating the arc domain from the Congo craton (Fig. 1). 


\section{Cratonic domains}

Comparing our thermochemical maps and the cratonic domains inferred by surface geology reveals both striking correlations and discrepancies. The Kaapvaal and Zimbabwe cratons are clearly identified in our model; both exhibit a relatively thick and highly depleted lithospheric mantle despite having been affected by plume activity and volcanism for at least $2000 \mathrm{Ma}$ (Large Igneous Provinces: 2055 Ma Bushveld, 1105 Ma Umkondo and ca. 180 Ma Karoo). This is also true for the region around Kimberley and Bloemfontein (Fig. 1c,d), which still retains a depleted and relatively thick lithosphere(170-200 km).

A corridor of more fertile mantle between the Kaapvaal and Zimbabwe cratons coincides broadly with the Limpopo Belt. The region affected by Bushveld-Molopo Farms magmatism within the Kaapvaal Craton also shows a more fertile composition, consistent with xenolith evidence ${ }^{24}$. The compositional structure retrieved by our inversion across the Kaapvaal Craton is in excellent agreement with that inferred from a regional study of mantle samples from 29 kimberlites $^{25}$ (10570 Ma; Suppl. Fig. 17; Fig. 1d). These independent validations are particularly important because our inversion is driven entirely by geophysical data, with no input from local xenolith information.

The Tanzanian Craton is visible in our model as a region of highly-depleted lithospheric mantle and relatively thick lithosphere $(\sim 150-200 \mathrm{~km})$, bounded by the branches of the East African Rift. The most depleted areas include localities where xenoliths/xenocrysts confirm highly refractory lithosphere (e.g. Igwisi, Mwadui and Nzega on the craton, and Labait on the craton margin). The map of Mg\# (Fig. 1) shows a clear separation between the Tanzanian craton and the Pro- 
terozoic Bangweulu block in the south. We do not see the previously proposed ${ }^{18}$ deep cratonic root beneath the southern Irumide Belt (Niassa craton). Although we obtain relatively high velocities in the mantle, the joint fit of all observables favours a small-scale sublithospheric downwelling rather than a thick lithospheric root (Suppl. Fig. 19). Since this orogenic belt experienced Mesoproterozoic convergence (including arc magmatism) and collision, Pan-African, Paleozoic and Tertiary thermal reworking and extensional tectonics ${ }^{26}$, it seems unlikely that its lithospheric mantle would retain cratonic characteristics. This highlights an important limitation of using seismic velocities alone to derive models of the $\mathrm{LAB}^{13,27}$. In regions where convective downwellings occur, the seismically-derived LAB will be overestimated due to the lack of sensitivity in separating convective from non-convective anomalies. That is, cold sublithospheric mantle in small-scale downwellings may be mistakenly interpreted as ancient cratonic roots.

Towards the north, the Tanzanian Craton extends to the boundary between Uganda and South Sudan; this is visible in both the Mg\# and LAB maps (Fig. 1). An important observation is that the Tanzanian and Congo cratons do not seem connected by a thick lithospheric "bridge" along and around the Aswa transform, as inferred from surface geology ${ }^{28}$ and from the observation that carbonatitic magmatism on the western side of the Tanzanian craton stops towards the north ${ }^{29}$. Our model offers an alternative explanation. Fig. 2a shows a large asthenospheric upwelling beneath the Tanzanian Craton (linked to the AFAR upwelling to the north); it branches off where it impinges on the root of the craton, also contributing to its high elevation. This results in asthenospheric material being focused towards the Western and Eastern rifts, where it reaches the shallower depths required to produce carbonatitic melts. In contrast, the asthenosphere towards 
the north participates in a forced downwelling triggered by the interaction between the adjacent AFAR upwelling (Fig 2b) and the surrounding lithospheric structure. Although the LAB in this region is relatively shallow $(\sim 100 \mathrm{~km})$, the local asthenospheric circulation impedes decompression melting. In the central part of the craton, kimberlitic magma generated at depths $>150 \mathrm{~km}$ has erupted during the Quaternary ${ }^{30}$ (Figs 2, 3), supporting this geodynamic scenario and our LAB estimates.

The lithosphere of the Congo Craton shows some striking and unexpected features. Its deepest roots, near the localities of Imese, Lisala and Llebo, extend below $260 \mathrm{~km}$ (Fig. 1). The eastern edge has been significantly eroded, forming a narrow corridor that focuses shallow asthenospheric upwellings (Figs. 1c, 2a). Similarly, the middle and western portions of the Angolan Shield have been thinned by at least $80 \mathrm{~km}$ since the intrusion of Triassic kimberlites (see above and Suppl. Fig. 16). Northwards, the Congo Craton is bounded by two major shear zones: the CASZ and the (inferred) northern continuation of the Aswa Shear Zone. The correlation between these shear zones and the sharp boundary of the craton suggests that the entire lithosphere has participated in strike-slip deformation and that such structures exerted a dominant role in the evolution of the LAB.

A modest thinning of the lithosphere propagates from northern Angola into the Kenge and Bandunu regions in Congo (Fig. 1). This feature coincides roughly with a compositional anomaly in the lithospheric mantle (Fig. 1) and with the junction of two important, long-lived trans-tensional structures: the Shangha aulacogen and the Dekese Trough ${ }^{31}$. The SW-NE-trending compositional 
anomaly dissects the Congo Craton, otherwise characterized by strongly-to-moderately depleted mantle, and joins a second anomaly along the eastern margin of the craton.

The thermochemical structure of the Congo Craton imaged here reconciles long-standing questions about the origin of the Congo Basin and the associated gravity/geoid anomaly. A late Neoproterozoic rift origin for the basin, followed by a long period ( $>560 \mathrm{Ma}$ ) of thermal relaxation, has been proposed on the basis of subsidence curves, stratigraphy and structural features of the basin ${ }^{32,33}$. Others have proposed that most of the subsidence reflects a downwelling in the sublithospheric mantle ${ }^{34}$. This downwelling would not affect lithospheric mantle composition, whereas rifting usually does. Indeed, there is abundant evidence of magmatism associated with extensional episodes ${ }^{33}$. Since the mantle compositional anomalies are spatially correlated with regions of known extension and magmatism in the craton, we suggest that the original depleted mantle root of the Congo Craton was refertilized during episodes of extension, increasing its density and thinning it locally. This assigns a clear meaning to the postulated need for a high-density anomaly within the lithospheric mantle $\mathrm{e}^{35}$ and resolves the problem ${ }^{32}$ of a thick and strongly depleted mantle root explaining both the gravity anomalies and the subsidence/topography. Although we cannot confidently constrain the chemical stratification of the lithospheric mantle, additional inversions (Suppl. Fig. 20) show only a slight preference for more depleted material at shallower depths. Lastly, we note that the LAB geometry surrounding and beneath the Congo Craton represents an ideal setting for the nucleation of gravitational instabilities in the asthenosphere, consistent with evidence from earthquake focal mechanisms and seismic tomography ${ }^{3,36}$. If downwellings nucleate beneath the Congo Craton, a dynamic effect would be seen in the topography and would 
have played a role in the recent subsidence history of the basin ${ }^{32,35}$. However, additional tests (Suppl. Fig. 21) demonstrate that our results are robust against dynamic effects.

\section{Implications for the evolution of cratonic lithosphere}

Our study shows that the Tanzanian, Zimbabwe, Kaapvaal and Bangweulu cratons/blocks have retained depleted compositions and relatively thick lithospheres in their cores. The Congo Craton, however, experienced significant refertilization during extension across the middle of the Congo basin (Fig. 1, Suppl. Fig. 17). Despite this, it remained a coherent block between two greatly thinned regions (CASZ and Angola), suggesting that any modification/thinning of the lithosphere beneath the Congo Basin was thermally/mechanically recovered by the time the Atlantic Ocean started opening ${ }^{32}$. This is likely given the recovery time following the Precambrian rifting and the tendency of thick roots to nucleate cold downwellings, which further favour lithospheric cooling. Also, no known plumes have affected this region in the past $300 \mathrm{Ma}$. Therefore, it is possible that the combined influence of the Tristan Plume and the already weakened and thinned CASZ preferentially localized upwellings and deformation beneath Angola and Cameroon, leaving the region between them affected only by slight compression due to return downwellings in the asthenosphere.

Another significant contrast in cratonic behaviour is exemplified by the differences between the Kaapvaal Craton and the southern margins of the Congo Craton. Hot-spot reconstructions indicate that the Kaapvaal experienced multiple episodes of plume activity (Fig. 3). Although 
there is evidence for lithospheric erosion by plumes $^{18}$ (Fig. 3), our results show that most of the Kaapvaal Craton has preserved a highly-depleted and thick lithosphere with a coherent core. In contrast, the western parts of the Angolan-Kasai shield and the Rehoboth block have lost their thick depleted keels. These regions, together with the eastern portions of the Damaran Belt, have been affected not only by plumes (Fig. 3) but also by Proterozoic convergent events and trans-tensional tectonics (except the Rehoboth Block) during the breakup of Pangea. It has been $\operatorname{argued}^{14}$ that the lower part of the Kaapvaal root was completely delaminated in the Cretaceous and replaced by cooled asthenospheric mantle. This is contradicted by Re-Os data for both xenoliths and sulfide grains from late Cretaceous kimberlites; Archean model ages are found throughout the lithospheric column, in both depleted and metasomatized samples ${ }^{37}$. Notwithstanding this, the correlation of hot-spot tracks with regions of refertilized mantle and kimberlitic volcanism (Fig. 3b) suggests a genetic link.

A pattern emerges from the evidence discussed above. Cratons share a number of features inherited from their formation/stabilization ${ }^{38}$, but their evolution and present-day thermochemical structure can differ remarkably depending on various geodynamic factors. Foremost among these are the presence of pre-existing weak zones in the lithosphere (e.g. past subduction zones, orogens, shear zones), the physico-chemical interaction between upwellings and lithospheric architecture, and the large-scale stress field. Pre-existing zones of weakness play a critical role in combination with mantle upwellings during continental breakup ${ }^{39}$ and studies of interactions between asthenospheric flow and craton geometry suggest that sharp craton margins, such as that imaged around the CASZ, are more resistant to deformation and erosion than gradual margins (e.g. Rehoboth 


\section{Block $)^{40}$.}

The improved ability to map the fine-scale thermochemical structure of the lithosphere and upper mantle provides a new integrative template for linking, validating and interpreting information from geochemical, geophysical and geodynamic studies. By harnessing land and satellite geophysical observations, our approach replicates detailed information from mantle xenoliths and therefore confidently extends the imaging to regions without xenolith data. We expect this approach to contribute to the development of next-generation planetary models and exploration strategies.

\section{Methods}

Databases The initial crustal model was constructed from CRUST1.0 ${ }^{41}$ and LithoRef1 $8^{42}$, and allowed to change during the MCMC inversion within a prescribed range (see below). Absolute elevation, surface heat flow, upper mantle geoid anomalies, gravity anomalies and gravity gradients were taken from refs. ${ }^{43,44,42,45,46}$, respectively. When the spatial resolution of a dataset was higher than that used in our model $\left(1^{o} \mathrm{x} 1^{\circ}\right)$, the original data were spatially averaged within a $1^{\circ} \times 1^{o}$ cell; the resulting mean values were then used as inputs and the standard deviations were considered when assigning overall uncertainties (see below). Note that this measure of spatial variability within a cell is typically larger than the true observational uncertainty of the field. Geoid anomalies

reported in ref. $^{42}$ (and used here) were filtered to minimize the effects of deep mantle density anomalies that are not considered in the inversion. Observed and predicted gravity gradients were compared at satellite height $(250 \mathrm{~km})$. 
A complete set of Rayleigh-wave dispersion curves was obtained by supplementing a global dataset $^{47}$ with higher-resolution, regional studies and by ambient noise tomography (ANT) for periods $<50$ secs in selected regions (Suppl. material, Fig. 1, 2). In particular, we used dispersion data from ref. ${ }^{48}$ in South Africa, ref. ${ }^{49}$ in Cameroon and ref..$^{50}$ in the East African Rift (see Suppl. material for period ranges; Suppl. Fig. 24 for regions covered by the regional tomography studies ${ }^{48-50}$ ). In regions without dispersion data, we computed dispersion curves in the period range $25-160 \mathrm{sec}$ at the points of interest from 1D velocity profiles extracted from the global model of ref. ${ }^{47}$. In doing so, we use a modified version of the software $\operatorname{disp} 96^{51,13}$ and the attenuation model of ref. ${ }^{52}$. To minimize unwanted artifacts due to truncation effects during the computation of dispersion curves at the longest periods, we extended the velocity-density structure of the mantle from the bottom of the inversion volume (410 km depth) down to $1500 \mathrm{~km}$ depth using the global model of ref. ${ }^{53}$. For the ANT, we processed data from 870 stations over 25 years of seismic noise recorded by 20 arrays (see Suppl. material). We used a standard noise cross-correlation technique with a time-frequency phase weighted stacking method to improve the signal to noise ratio ${ }^{54,55}$. Suppl. Fig. 2 shows examples of the resultant dispersion curves and their uncertainties.

We did not consider radial anisotropy in our inversions. Radial anisotropy in the upper mantle causes the vertically polarised Vsv (and the associated Rayleigh-wave phase velocity) to differ from the isotropic average $\mathrm{Vs}_{i s o}$ of the mantle assemblage $\left(\mathrm{e} . \mathrm{g} . \mathrm{Vs}_{i s o}=(\mathrm{Vsv}+\mathrm{Vsh}) / 2\right)$. Horizontally oriented fabrics produce positive radial anisotropy (Vsh $>V s v)$ whereas vertical fabrics result in negative anisotropy (Vsh $<$ Vsv). This would result in a bias towards higher (lower) temperatures in our model in regions of strong positive (negative) radial anisotropy. The radial anisotropy 
of the African continent is still subject to large uncertainties, but some studies have shown that it i) varies within only a few percent laterally, ii) decreases with depth, and iii) is generally positive in the first $200 \mathrm{~km}^{56}$. Although estimating the bias is not straightforward due to the many factors that contribute to the inverted temperature structure, exploratory inversions indicated that the effects of radial anisotropy on our temperature and LAB estimates are well within $1 \sigma$ of the obtained posterior distributions as long as the average anisotropy in the first $200 \mathrm{~km}$ is $\lesssim 3 \%$. In this respect, we note that our temperatures agree well with thermobarometric estimates from the youngest xenoliths in the Kaapvaal and Tanzanian cratons (Suppl. Fig. 28).

Multi-observable probabilistic inversion All datasets were jointly inverted with a thermodynamicallyconstrained, multi-observable probabilistic inversion method ${ }^{11-13}$, coded into two fortran packages: LitMod1D_4INV and LitMod3D_4INV (https://www.juanafonso.com/software). This method is specifically designed to obtain estimates of the physical state (e.g. temperature distribution, compositional structure, stress/strain distributions, etc.) of the lithosphere and sublithospheric upper mantle by inverting multiple datasets with the necessary complementary sensitivities to the main fields of interest. The inverse problem is cast into a statistical (Bayesian) inference problem ${ }^{11,12}$. Consequently, the solution to the inverse problem is represented by a multi-dimensional probability distribution (known as the posterior distribution) over the parameters of interest. For parameter estimation problems, the posterior distribution can be written as $\pi(\mathbf{m}) \propto L(\mathbf{m}) \rho(\mathbf{m})$, where $\mathbf{m}$ is the vector of model parameters, $\rho(\mathbf{m})$ is the prior distribution describing all the information in the parameter space that is independent from the actual measurements, and $L(\mathbf{m})$ is the likelihood function, which describes the probability of obtaining the observed data given $\mathbf{m}$ (i.e. a measure of 
how good the model $\mathbf{m}$ is in explaining the data). Under the assumption of Gaussian uncertainties in the data and model predictions, the likelihood can be written as $L(\mathbf{m}) \propto \exp [-S S(\mathbf{m})]$, where $S S(\mathbf{m})$ is the misfit function that measures the discrepancy between observed and predicted data for all datasets (see below). Since $\pi(\mathbf{m})$ has no analytical solution, we sample it by constructing a Markov chain that has the posterior distribution has its equilibrium distribution. To do so, we used the Delayed Rejection Adaptive Metropolis algorithm of ref. ${ }^{57}$ during the exploratory 1D stage and the Multiple-Try Metropolis algorithm of ref. ${ }^{58}$, combined with proposal adaptivity, during the 3D refinement stage (see refs. ${ }^{11}$ and ${ }^{12}$ for details on the set up of the two stages). The final inversions were run in the MG3 cluster at Macquarie University and involved $42 \times 10^{6}$ and $10 \times 10^{6}$ simulations for the $1 \mathrm{D}$ and $3 \mathrm{D}$ stages, respectively.

In contrast to more traditional inversion methods, we invert directly for the main thermodynamic variables temperature, pressure and major-element composition $\left(\mathrm{CaO}, \mathrm{FeO}, \mathrm{MgO}, \mathrm{Al}_{2} \mathrm{O}_{3}\right.$, $\mathrm{SiO}_{2}$ ) at specific locations inside our model. More specifically, the mantle is discretized with 20,955 nodes where the full Gibbs free-energy minimization is performed at each MCMC iteration using components of the software Perple_ $\mathrm{X}^{59}$ and adopting the thermodynamic model and internally-consistent database of ref. ${ }^{60}$. This provides the link between the main thermodynamic variables and the physical parameters needed to solve the forward problems (e.g. density, bulk modulus) and guarantees that our models will not violate fundamental thermodynamic relations. This is a crucial aspect, as the link between bulk density and seismic velocities (and the data sensitivity to these parameters) controls our ability to discriminate between thermal and compositional fields ${ }^{10-13}$. We do not solve the thermodynamic problem in the crust, where Birch's law is gen- 
erally obeyed. Instead, we link densities and seismic velocities using the empirical equations in ref. $^{61}$. During the inversion, we compute $1 \mathrm{D}$ steady-state conductive geotherms in each cell down to the LAB (a model parameter sampled during the inversion), which we identify with the depth to the $1250{ }^{\circ} \mathrm{C}$ isotherm. The geotherm in the sublithospheric mantle is obtained as a linear interpolation between 3-6 (dependent on the LAB depth) nodes whose temperature is considered unknown and sampled during the inversion. For further details on the method, see refs. ${ }^{11-13}$.

Misfit function Following the arguments in ref. ${ }^{13}$, we choose the following form for the misfit function of 2D fields (e.g. elevation, gravity anomaly, geoid).

$$
S S^{j}(\mathbf{m})=\sum_{i=1}^{N} \frac{\left(d_{i}^{\text {calc }}-d_{i}^{\text {obs }}\right)^{2}}{\sigma_{i}^{2}}
$$

where $N$ is the numbers of columns and $j$ is the type of 2D data. For dispersion data, we use

$$
S S(\mathbf{m})=\sum_{i=1}^{N} \sum_{k=1}^{N_{p e r}} \frac{\left(d_{i k}^{c a l c}-d_{i k}^{o b s}\right)^{2}}{\sigma_{i k}^{2}}
$$

where $N_{p e r}$ is the number of periods used to represent the dispersion curve. The values of $\sigma$ come from considering the uncertainties arising from i) errors in the observed data, ii) averaging data over the area of each $1^{\circ} \times 1^{\circ}$ column and iii) errors in the predicted data. In most cases, the last two dominates the final uncertainty ${ }^{11,13}$. Here we used minimum, yet generous, uncertainties of $150 \mathrm{~m}$ for elevation, $5 \mathrm{mGal}$ for gravity anomalies, 0.05 Eötvös for gravity gradients and $1 \mathrm{~m}$ for geoid. For Rayleigh wave phase velocities, we assigned different uncertainties based on the type of 
data used in specific regions (see Suppl. Figs. 22-25 for examples of data fits). Since the datasets used in this study have different units, uncertainties, data coverage and sensitivities to different aspects of the problem, the simultaneous inversion of these data requires an adequate weighting of each dataset. This avoids solutions that are dominated by one dataset or by nonphysical factors (e.g. data density or discretization, inherent incompatibilities between datasets). Therefore, the final misfit is obtained as the weighted sum of all the misfits above: $\phi_{\text {total }}=\sum_{l} \frac{S S^{l}}{w_{l}}$. The weights $w_{l}$ used in the final inversions were chosen based on the performance of ten preliminary inversions.

1. Griffin, W., Begg, G. and O'Reilly, S. Continental-root control on the genesis of magmatic ore deposits. Nature Geosci 6, 905-910 (2013).

2. Holwell, D.A., Fiorentini, M., McDonald, I. et al. A metasomatized lithospheric mantle control on the metallogenic signature of post-subduction magmatism. Nat Commun 10, 3511 (2019).

3. Craig, T.J., Jackson, J.A., Priestley, K. and McKenzie, D., Earthquake distribution patterns in Africa: their relationship to variations in lithospheric and geological structure, and their rheological implications. Geophysical Journal International, 185: 403-434, (2011).

4. Hoggard, M.J., Czarnota, K., Richards, F.D. et al. Global distribution of sediment-hosted metals controlled by craton edge stability. Nat. Geosci. 13, 504-510 (2020).

5. Begg, GG., J.M.A. Hronsky, W.L. Griffin, S.Y. O’Reilly, Global- to deposit-scale controls on orthomagmatic Ni-Cu(-PGE) and PGE reef ore formation, in: S.K. Mondal, W.L. Griffin (Eds.), Processes and Ore Deposits of Ultramafic-Mafic Magmas through Space and Time, Elsevier, pp. 1-46 (2018). 
6. Heinson, G., Didana, Y., Soeffky, P. et al. The crustal geophysical signature of a world-class magmatic mineral system. Sci Rep 8, 10608 (2018)

7. Begg, G., J.M.A. Hronsky, N.T. Arndt, W.L. Griffin, S.Y. O'Reilly, N. Hayward, Lithospheric, cratonic, and geodynamic setting of Ni-Cu-PGE sulfide deposits, Econ. Geol., 105 (6) (2010).

8. Schutt, D. L., and Lesher, C. E., Effects of melt depletion on the density and seismic velocity of garnet and spinel lherzolite, J. Geophys. Res., 111, B05401, (2006).

9. O'Reilly SY, Griffin WL. Imaging chemical and thermal heterogeneity in the sub-continental lithospheric mantle with garnets and xenoliths: Geophysical implications, Tectonophysics, 416, (2006).

10. Afonso, J.C., G. Ranalli, M. Fernandez, W. L. Griffin, S. Y. O’Reilly, and U. Faul, On the $\mathrm{Vp} / \mathrm{Vs}-\mathrm{Mg} \#$ correlation in mantle peridotites: Implications for the identification of thermal and compositional anomalies in the upper mantle, Earth Planet. Sci. Lett., 289, (2010).

11. Afonso, J. C., Fullea, J., Griffin, W. L., Yang, Y., Jones, A. G., D. Connolly, J. A., and O'Reilly, S. Y., 3-D multi-observable probabilistic inversion for the compositional and thermal structure of the lithosphere and upper mantle. I: a priori petrological information and geophysical observables, J. Geophys. Res. Solid Earth, 118 (2013a).

12. Afonso, J. C., Fullea, J., Yang, Y., Connolly, J. A. D., and Jones, A. G., 3-D multi-observable probabilistic inversion for the compositional and thermal structure of the lithosphere and upper mantle. II: general methodology and resolution analysis, J. Geophys. Res. Solid Earth, 118, (2013b). 
13. Afonso, J. C., Rawlinson, N., Yang, Y., Schutt, D. L., Jones, A. G., Fullea, J., and Griffin, W. L., 3-D multiobservable probabilistic inversion for the compositional and thermal structure of the lithosphere and upper mantle: III. Thermochemical tomography in the Western-Central U.S., J. Geophys. Res. Solid Earth, 121, (2016).

14. Hu, J., Liu, L., Faccenda, M. et al. Modification of the Western Gondwana craton by plume-lithosphere interaction. Nature Geosci 11, 203-210 (2018).

15. Grand, S., Mantle Shear-Wave Tomography and the Fate of Subducted Slabs. Philosophical Transactions: Mathematical, Physical and Engineering Sciences, 360, (2002).

16. Ritsema J., Van Heijst, H.J., Seismic imaging of structural heterogeneity in Earth's mantle: evidence for large-scale mantle flow. Sci Prog., 83, 243-59, (2000).

17. Fishwick, S., Surface wave tomography: Imaging of the lithosphere-asthenosphere boundary beneath central and southern Africa? Lithos, 120, 63-73, (2010).

18. Celli, N.L., Lebedev, S., Schaeffer, A.J. et al. African cratonic lithosphere carved by mantle plumes. Nat Commun 11, 92 (2020).

19. Torsvik, T.H., Rousse, S., Labails, C. and Smethurst, M.A., A new scheme for the opening of the South Atlantic Ocean and the dissection of an Aptian salt basin. Geophys. J. Int., 177, 1315-1333, (2009).

20. Yuan, X., Heit, B., Brune, S., Steinberger, B., Geissler, W. H., Jokat, W., and Weber, M., Seismic structure of the lithosphere beneath NW Namibia: Impact of the Tristan da Cunha mantle plume, Geochem. Geophys. Geosyst., 18, 125-141, (2017). 
21. Jelsma, H. et al., Kimberlites from Central Angola: A case study of exploration findings, 10th Int. Kimberlite Conf., 10IKC-42 (2012).

22. Giuliani, A, Campeny, M, Kamenetsky, VS , Afonso, JC, Maas, R, Melgarejo, JC, Kohn, BP, Matchan, EL, Mangas, J, Goncalves, AO and Manuel, J., Southwestern Africa on the burner: Pleistocene carbonatite volcanism linked to deep mantle upwelling in Angola, Geology, 45, 971-974 (2017).

23. Hopper, E., Gaherty, J.B., Shillington, D.J. et al. Preferential localized thinning of lithospheric mantle in the melt-poor Malawi Rift. Nat. Geosci. 13, 584-589 (2020).

24. Hoal, K.E.O., Samples of Proterozoic Fe-enriched mantle form the Premier kimberlite. Lithos, 71, 259-272 (2003).

25. Kobussen, A. F., W. L. Griffin, and S. Y. O’Reilly, Cretaceous thermo-chemical modification of the Kaapvaal cratonic lithosphere, South Africa, Lithos, 112, 886-895 (2009).

26. Fritz, H., M. Abdelsalam, et al., Orogen styles in the East African Orogen: a review of the Neoproterozoic to Cambrian tectonic evolution, J. African Earth Sci., 86, 65-106 (2013).

27. Eaton DW, Darbyshire F, Evans RL, Grutter H, Jones AG, Yuan X., The elusive lithosphereasthenosphere boundary (LAB) beneath cratons. Lithos 109, 1-22 (2009).

28. Link, K., Koehn, D., Barth, M.G. et al. Continuous cratonic crust between the Congo and Tanzania blocks in western Uganda. Int. J. Earth Sci. 99, 1559-1573 (2010). 
29. Rosenthal A, Foley SF, Pearson DG, Nowell GM, Tappe S., Magmatic evolution at the propagating tip of a continental rift - a geochemical study of primitive alkaline volcanic rocks of the western branch of the East African Rift. Earth Planet Sci Lett 284, 236-248 (2009).

30. Dawson J B., Quaternary kimberlitic volcanism on the Tanzania Craton, Contrib. Min. Petrol., 116, 473-485 (1994).

31. Alvarez, P., Evidence for a Neoproterozoic carbonate ramp on the northern edge of the Central Africa craton: relations with Late Proterozoic intracratonic troughs, Geol. Rundsch., 84, 636$648(1995)$.

32. Crosby, A. G., Fishwick, S., and White, N., Structure and evolution of the intracratonic Congo Basin, Geochem. Geophys. Geosyst., 11, Q06010 (2010)

33. Kadima, E., Delvaux, D., Sebagenzi, S.N., Tack, L. and Kabeya, S.M., Structure and geological history of the Congo Basin: an integrated interpretation of gravity, magnetic and reflection seismic data. Basin Research, 23, 499-527 (2011).

34. Hartley, R. W., and P. A. Allen, Interior cratonic basins of Africa: Relation to continental break-up and role of mantle convection, Basin Res., 6, 95-113 (1994).

35. Downey, N. J., and Gurnis, M., Instantaneous dynamics of the cratonic Congo basin, J. Geophys. Res., 114, B06401 (2009).

36. Forte, A. M., S. Quéré, R. Moucha, N. A. Simmons, S. P. Grand, J. X. Mitrovica, and D. B. Rowley, Joint seismic-geodynamic-mineral physical modeling of African geodynamics: A 
reconciliation of deep mantle convection with surface geophysical constraints, Earth Planet. Sci. Lett., 295, 329-341 (2010).

37. Griffin, W.L., Graham, S., O'Reilly, S.Y. and Pearson, N.J., Lithosphere evolution beneath the Kaapvaal Craton. Re-Os systematics of sulfides in mantle-derived peridotites. Chemical Geology 208, 89-118, (2004).

38. Capitanio, F.A., Nebel, O. and Cawood, P.A. Thermochemical lithosphere differentiation and the origin of cratonic mantle. Nature 588, 89-94 (2020).

39. Dang, Z., Zhang, N., Li, ZX. et al. Weak orogenic lithosphere guides the pattern of plumetriggered supercontinent break-up. Commun Earth Environ 1, 51 (2020).

40. C.M. Cooper, R.J. Farrington, M.S. Miller, On the destructive tendencies of cratons. Geology, 49, 195-200 (2020).

41. Laske G, Master G, Ma Z, Pasyanos M. Update on CRUST1. 0-A 1-degree global model of Earth's crust, Geophysical Research Abstract, 15, (2013).

42. Afonso JC, Salajegheh F, Szwillus W, Ebbing J, Gaina C. A global reference model of the lithosphere and upper mantle from joint inversion and analysis of multiple data set, Geophys. J. Int., 217, (2019).

43. Amante C, Eakins B W., ETOPO1 arc-minute global relief model: procedures, data sources and analysis, (2009). 
44. Goutourbe B, Poort J, Lucazeau F, Raillard S. Global heat flow trends resolved from multiple geological and geophysical proxies, Geophys. J. Int., 187, (2011).

45. Bonvalot, S., Balmino, G., Briais, A., M. Kuhn, Peyrefitte, A., Vales N., Biancale, R., Gabalda, G., Reinquin, F., Sarrailh, M., World Gravity Map. Commission for the Geological Map of the World. Eds. BGI-CGMW-CNES-IRD, Paris (2012)

46. Kvas A, Behzadpour S, Ellmer M, Klinger Beate, Strasser S, Zehentner N, Mayer-Gurr T. ITSG-Grace2018: Overview and evaluation of a new GRACE-only gravity field time series, Journal of Geophysical Research : Solid Earth, 124, (2019).

47. Schaeffer, A. J. and Lebedev, S. Global shear speed structure of the upper mantle and transition zone. Geophys. J. Int. 194, 417-449 (2013).

48. Yang Y, Li A, Ritzwoller MH. Crustal and uppermost mantle structure in southern Africa revealed from ambient noise and teleseismic tomography, Geophysical Journal International, 174, (2008).

49. Adams AN, Wiens, DA, Nyblade AA, Euler GG, Shore PJ, Tibi R. Lithospheric instability and the source of the Cameroon Volcanic Line: Evidence from Rayleigh wave phase velocity tomography. Journal of Geophysical Research: Solid Earth, 120, (2015).

50. O’Donnell JP, Adams A, Nyblade AA, Mulibo GD, Tugume F. The uppermost mantle shear wave velocity structure of eastern Africa from Rayleigh wave tomography: Constraints on rift evolution, Geophys. J. Int., 194, (2013). 
51. Herrmann, R.B., Computer Programs in Seismology, Version 3.3, St. Louis University (Available at http://www.eas.slu.edu/eqc/eqcsoftware.html).

52. Dalton, C. A., Ekström, G., Dziewonski, A. M., The global attenuation structure of the upper mantle, J. Geophys. Res., 113, B09303, (2008).

53. Simmons, N. A., Forte, A. M., Boschi, L., Grand, S. P., GyPSuM: A joint tomographic model of mantle density and seismic wave speeds, J. Geophys. Res., 115, B12310 (2010).

54. Schimmel M, Gallart J. Frequency-dependent phase coherence for noise suppression in seismic array data, Journal of Geophysical Research: Solid Earth, 112, (2007).

55. Li G, Niu F, Yang Y, Xie J. An investigation of time-frequency domain phase-weighed stacking and its application to phase-velocity extraction from ambient noise's empirical Green's functions, Geophys. J. Int., 212, (2018).

56. Sebai, A., Stutzmann, E., Montagner, J.-P., Sicilia, D., Beucler, E., Anisotropic structure of the African upper mantle from Rayleigh and Love wave tomography. Physics of the Earth and Planetary Interiors, 155(1-2), 48-62, (2006).

57. Haario H, Laine M, Mira A, Saksman E. DRAM: efficient adaptive MCMC, Statistics and computing, 16, (2006).

58. Liu JS, Liang F, Wong W H. The multiple-try method and local optimization in Metropolis sampling, Journal of the American Statistical Association, 95, (2000). 
59. Connolly J.A., The geodynamic equation of state: what and how. Geochemistry, Geophysics, Geosystems,10, (2009).

60. Stixrude L, Lithgow-Bertelloni C. Thermodynamics of mantle minerals-II. Phase equilibria, Geophysical Journal International, 184, (2011).

61. Brocher, T.M., Empirical relations between elastic wavespeeds and density in the Earth's crust, Bulletin of the Seismological Society of America, 95, 2081-2092 (2005).

Acknowledgements We thank S. Lebedev and two anonymous reviewers for their helpful suggestions. WBM and JCA acknowledge funding from ARC Grant DP160103502, ARC CE110001017, ARC Linkage Grant LP170100233, and Macquarie University DVCR co-funding scheme. This is contribution 1681 from the ARC Centre of Excellence for Core to Crust Fluid Systems (www.ccfs.mq.edu.au) and 1480 in the GEMOC Key Centre (http://www.gemoc.mq.edu.au).

Competing Interests The authors declare no competing interests.

Contributions JCA, NJ, AM and WBM conceived the project. WBM, JCA, FS and IF performed the inversions and processed all data sets and results. All authors analysed the results and contributed to writing the manuscript.

Data availability The data that support the findings of this study are available from the corresponding author upon reasonable request.

Code availability The codes used to perform the inversions are available from the corresponding author upon reasonable request. 
Figure 1 a) Political/topographic map of the study region; black text indicate abbreviations of country names. White stars indicate localities mentioned in the text. b) Cratons, pre-Cambrian blocks and other relevant tectonic features. c) Depth to the lithosphereasthenosphere boundary (LAB), here taken as the depth to the $1250{ }^{\circ} \mathrm{C}$ isotherm; major tectonic domains/features are also shown. d) Average $\mathrm{Mg} \#\left[\mathrm{Mg} /\left(\mathrm{Mg}+\mathrm{Fe}^{2+}\right)\right]$ in the lithospheric mantle as constrained in (c), with $\mathrm{Mg} \#$ in olivine from mantle xenoliths reported in the literature.

Figure 2 3D renderings of the thermal structure beneath the study area. The eruption ages of kimberlitic and carbonatitic volcanism are indicated with coloured spheres and boxes, respectively. The surface projections of the vertical cross-sections are indicated by the red lines over the topography. a) A hot upwelling beneath the Tanzanian Craton (TCR) impinges on the LAB and diverts toward its sides, focusing shallow decompression melting along the Western and Eastern branches of the East Africa Rift. In addition to the young volcanism along the edges of the craton, Quaternary kimberlitic volcanism generated at depths $>150 \mathrm{~km}^{32}$ occurred in the middle of the craton, above the high temperature anomaly (NV = Nyiragongo volcano). A smaller temperature anomaly, probably associated with a sublithospheric upwelling, is visible beneath Angola (AU). b) A forced sublithospheric downwelling towards the north of the Tanzanian Craton, which precludes the generation of decompression melting in the mantle, results from the mechanical interaction between the large AFAR upwelling and the adjacent lithospheric structure. 
Figure 3 a) Depth to the LAB. b) Average composition of the lithospheric mantle (as Mg\#). c) Moho depth. Locations of kimberlite (circles) and carbonatitic (squares) volcanics with reliable ages (colour scale) are shown. Hot-spot tracks (from ref. ${ }^{14}$ ) are denoted by dashed lines and diamonds; their colours represent the age at which the hot spot was at that location. 


\section{Elevation}

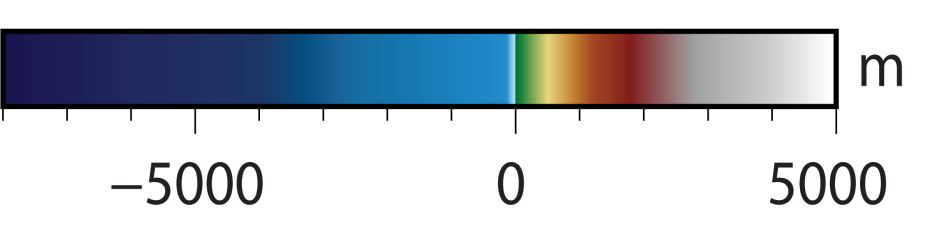

ASZ : Aswa shear zone

$\mathrm{BL}$ : Bloemfontain

CVC : Catanda volcanic complex CASZ : Central African Shear Zone DT: Dekese Trough

ER : Eastern Rift

IB : Irumide belt

IM : Imese

$\mathrm{KI}$ : Kimberley

LA : Lufulian arc

$\mathrm{LI}$ : Lisala

LL : Llebo

MSZ : Mwembeshi Shear zone MR : Malawi Rift

NV : Nyiragongo volcano

OL : Okahandja Lineament

ST: Sangha Trough

TVSZ : Tantalite Valley Shear Zone WR : Western Rift

Congo, Tanzanian and Kalahari Cratons

Cratonic blocks

AC: Angola craton

$\mathrm{BB}$ : Bangweulu block

GC: Gabon-Cameroon block

KB : Kasai block

KC: Kaapvaal craton

TC : Tanzanian craton

ZC : Zimbabwe craton

, - Structural lineaments Rehoboth block (RB)

Major shear zones

Major linear structures

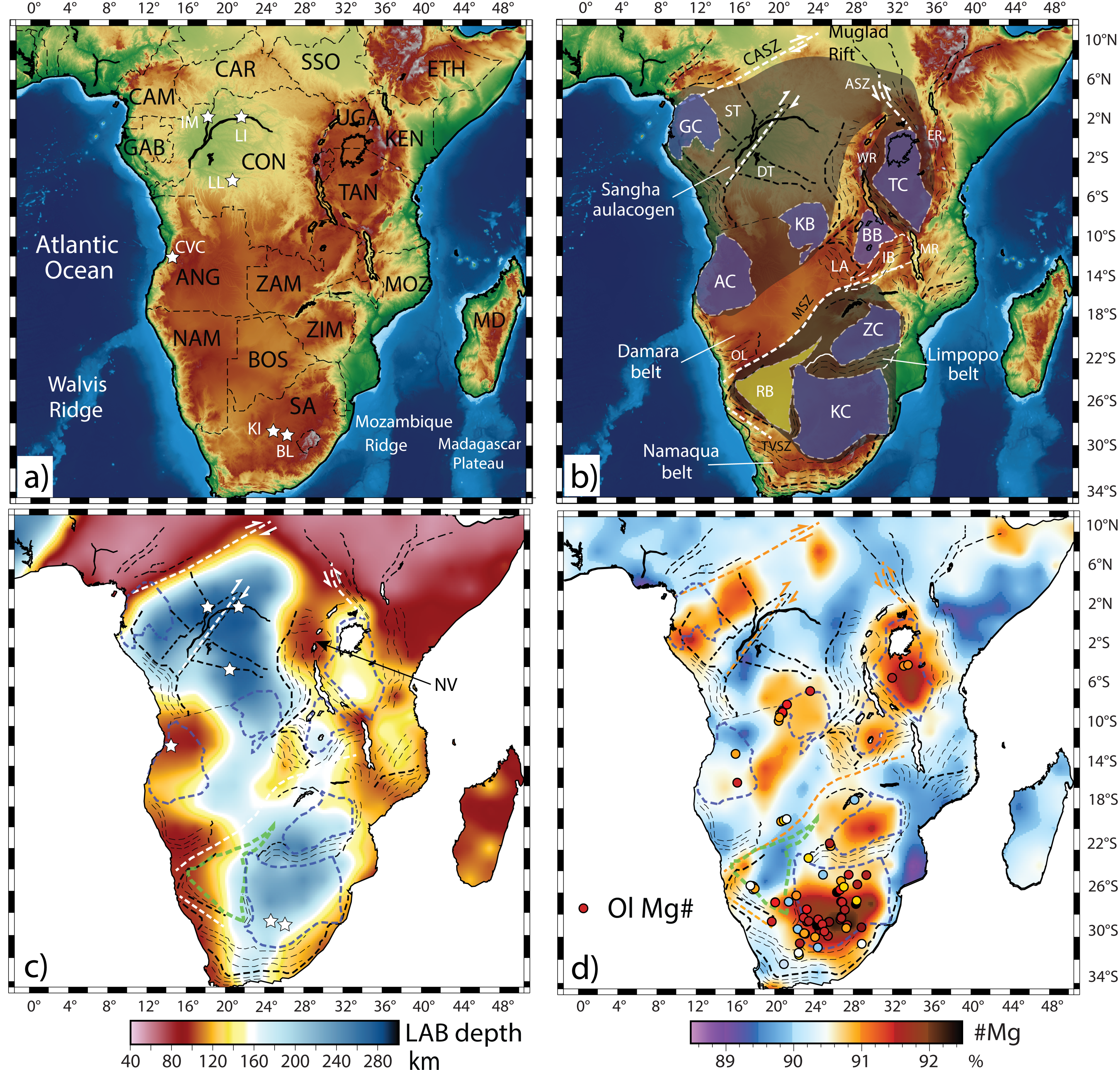

$\begin{array}{lllllllll}40 & 80 & 120 & 160 & 200 & 240 & 280 & \mathrm{~km}\end{array}$ $\begin{array}{llll}89 & 90 & 91 & 92\end{array}$ 

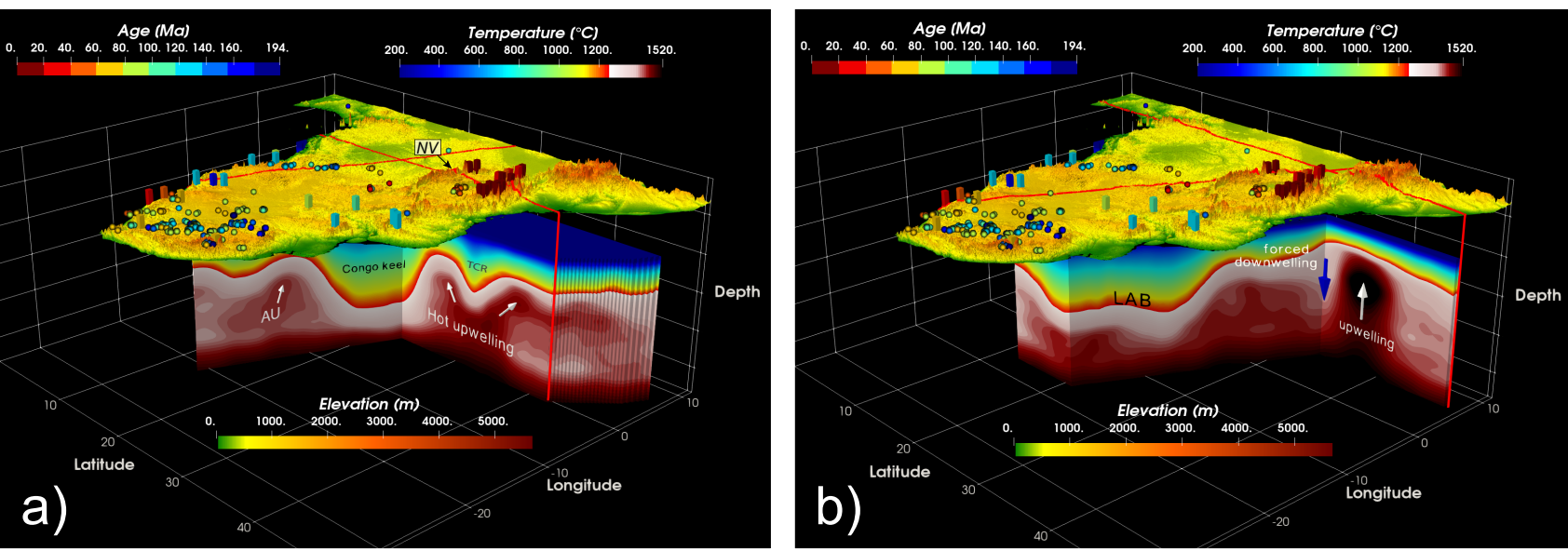
